\title{
Editorial: Elucidating Microbial Processes in Soils and Sediments: Microscale Measurements and Modeling
}

\author{
Philippe C. Baveye ${ }^{1 *}$, Wilfred Otten ${ }^{2}$ and Alexandra Kravchenko ${ }^{3}$ \\ ${ }^{1}$ UMR ECOSYS, AgroParisTech, Université Paris-Saclay, Paris, France, ${ }^{2}$ School of Water, Energy and Environment, Cranfield \\ University, Cranfield, United Kingdom, ${ }^{3}$ Department of Plant, Soil and Microbial Science, Michigan State University, East \\ Lansing, MI, United States
}

Keywords: microbial ecology, carbon sequestration, soil organic matter, greenhouse gas production, dynamics, modeling

Editorial on the Research Topic

Elucidating Microbial Processes in Soils and Sediments: Microscale Measurements and Modeling

Over the last decade, soils have become increasingly central to a number of crucial debates on issues of great societal concern, related to climate change, environmental pollution, or feeding

OPEN ACCESS

Edited and reviewed by: Denis Angers, Agriculture and Agri-Food Canada (AAFC), Canada

*Correspondence: Philippe C. Baveye baveye.rpi@gmail.com

Specialty section:

This article was submitted to Soil Processes,

a section of the journal

Frontiers in Environmental Science

Received: 02 May 2019 Accepted: 20 May 2019

Published: 07 June 2019

Citation:

Baveye PC, Otten W and Kravchenko A (2019) Editorial: Elucidating Microbial Processes in Soils and Sediments: Microscale

Measurements and Modeling.

Front. Environ. Sci. 7:78.

doi: 10.3389/fenvs.2019.00078 the estimated 10 billion people who will live on earth by 2050, a mere 30 years from now (Baveye, 2015). In order to successfully meet the extremely daunting challenges that confront us in these different contexts, we need to understand what controls the growth and activity of the soil microorganisms that mediate many if not most of the underlying processes. However, the information we have in this respect is still woefully inadequate, arguably at least in part because of a lack of appropriate technology.

Half a century ago, soil microbiologists reached the conclusion that a full understanding of the growth and activity of microorganisms in soils and sediments would require quantitative observations at spatial scales as near as possible to the size of the organisms themselves (Alexander, 1964). Back then, this type of observation was not feasible at all, unfortunately. The development of electron microscopes in the $60 \mathrm{~s}$ and $70 \mathrm{~s}$ provided qualitative insight into microscopic parameters that controlled the activity of bacteria, archaea, and fungi in pore spaces (Foster, 1988), but produced no quantitative information. It is only with the technological advances in X-ray computed micro-tomography $(\mu \mathrm{CT})$, first at synchrotron facilities in the 90s, then with commercial table-top scanners in the early 2000s, that quantitative, micrometric data on the geometry of the pore space has finally become available. In the last decade, different methods have also been developed to measure the spatial distribution of microorganisms at fine resolution in thin sections (e.g., Nunan et al., 2001), as well as to map the composition of organic soil constituents (e.g., Solomon et al., 2005) or the nature of nitrogenous compounds at micrometric or even nanometric scales (e.g., Mueller et al., 2012, 2017).

After these novel techniques became available, an initial stage in the research has consisted of identifying and resolving the problems associated with their use to elucidate microbial processes in heterogeneous soils and sediments. Significant progress has been achieved in this respect, for example in the development of objective (operator-independent), local segmentation techniques 
adapted for X-ray $\mu$ CT images [e.g., (Schlüter et al., 2010; Hapca et al., 2013; Houston et al., 2013a,b)], in terms of improvements of hybridization (FISH) technologies to locate bacterial and archaeal cells in soil thin sections (Eickhorst and Tippkötter, 2008; Schmidt et al., 2012), or in the in elaboration of statistical tools to interpolate 2-D measurements to produce $3-\mathrm{D}$ data (Hapca et al., 2011, 2015).

Shortly before the Research Topic on "Elucidating microbial processes in soils and sediments" was launched in August 2017, we felt that the time had come to switch to a higher gear, more focused on interdisciplinarity, in the research in this area, and we were convinced that encouraging our colleagues to submit jointly a number of manuscripts describing their work on this topic was the best approach to pave the way for this switch to occur. As part of the Research Topic, it was decided that a comprehensive review article would be put together, covering as much as possible of the relevant literature, and trying to identify major axes, or "paths," in it. In the resulting article (Baveye et al.), we identify three major disciplinary paths along which research efforts have taken place in the last 15 years, and which, when they will eventually converge in full interdisciplinary mode, should provide a far better grasp than what is currently available of what controls the activity of microorganisms in soils. The key take-home message of Baveye et al.'s review, visualized in Figure 1, is that significant progress has been achieved on a number of fronts, but that progress unfortunately is very uneven. At the extremes of the spectrum are the research on the physical characteristics of soils at the microscale and the (arguably more complicated) experimental observation of microbial processes. While the former has moved full speed ahead, the latter has been lagging far behind, casting doubt on the soundness of some of the modeling that has been carried out in this field, and hindering the needed integration of physical, (bio)chemical, and microbiological perspectives. Clearly, the picture that emerges from the extensive literature covered in Baveye et al.'s review suggests that, as of 2018, there was still a long way to go before reaching the Holy Grail, with many daunting challenges on the different paths leading to it.

In more ways than one, the various articles published as part of our Research Topic have managed, if not to reach the Holy Grail (that may have been a bit much to hope for), at least to address some of the challenges head on, and to make significant progress concerning quite a few of them.

A first group of articles focuses on the characterization of the geometry of the pore space, in which all the (bio)chemical and microbial processes take place in soils, and deepens our understanding of how this geometry as well as the architecture of the solid phase influence, or are symptomatic of, soil behavior. San José Martinez et al. explore the ability of Minkowski functionals of the connected soil pore space to discriminate between the pore geometries exhibited by soils with different managements and depths, and that are therefore expected a priori to be dissimilar. The crucial question of how well microscale measurements carried out via X-ray microtomography can help us unravel the relationship between microscopic soil architecture and macroscopic soil properties is addressed by Smet et al. These

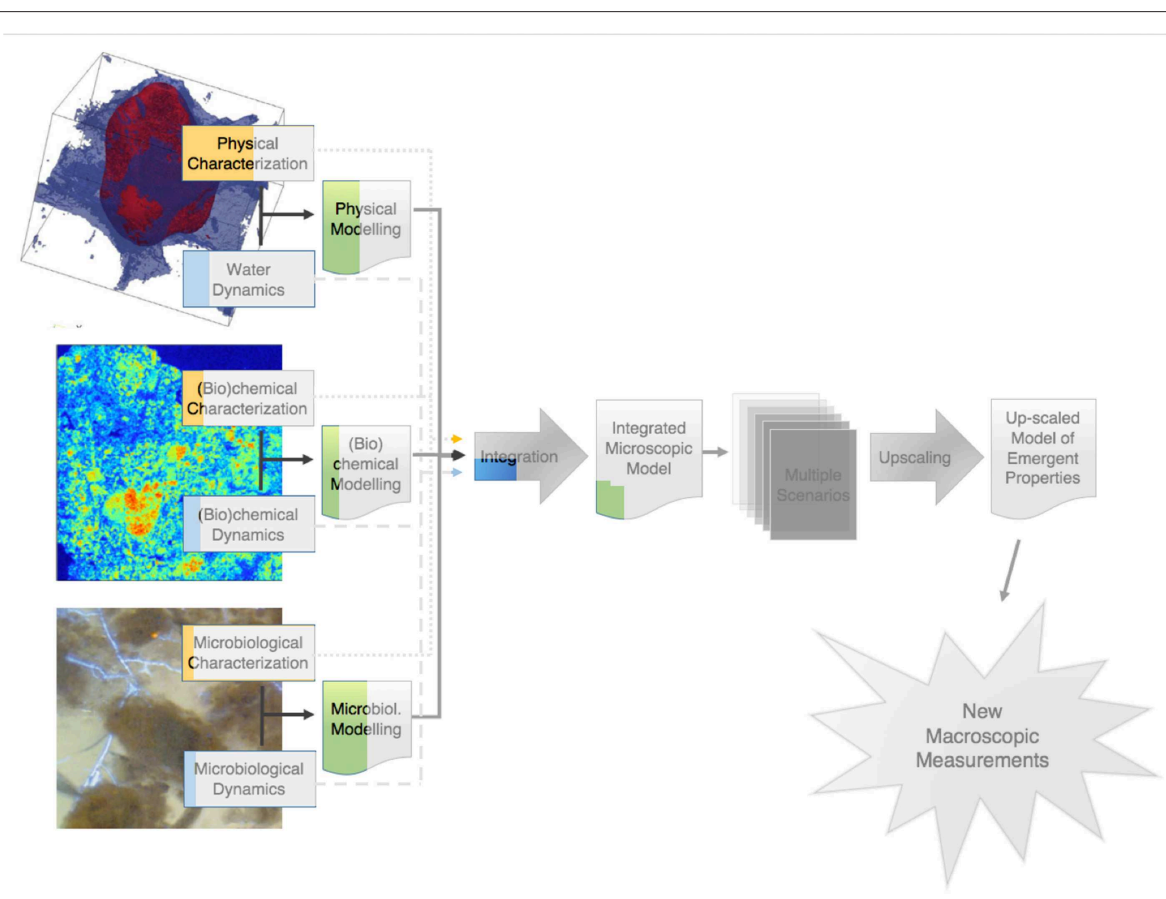

FIGURE 1 | Visual assessment of the level of progress along various paths in the research on the emergent properties of microbial activity in heterogeneous soil microenvironments. The colored parts correspond to Baveye et al.'s estimate of the progress achieved to date along each path. The shaded portions of the diagram still largely remain to be tackled. 
authors deal in particular with practical questions associated with the implementation of X-ray computed microtomography, including how well the samples represent the uniqueness of the pore network or architecture, and the systemic compromise between sample size and resolution.

A second group of four articles deals with the "hot" topic of the distribution and fate of soil organic matter (SOM). Maenhout et al. are interested in the impact of soil structure on $\mathrm{N}$ availability to microbes, and thus on heterotrophic microbial activity and community structure. Their results with artificially reconstructed miniature soil cores with contrasting soil structures, viz. high or low degree of contact between soil particles ascertained via X-ray $\mu \mathrm{CT}$, suggest that soil structure controls carbon mineralization through mediation of $\mathrm{N}$ diffusion and in turn $\mathrm{N}$ availability. Working with aggregates from a California forest and a Nevada shrubland soil subjected to different soil moisture and "heating" regimes, Jian et al. show that low-severity fires can accelerate the decomposition of soil organic carbon (SOC) protected in soil aggregates. Quigley et al. try to characterize the spatial heterogeneity of the soil matrix in macroaggregates obtained from soils associated with three contrasting longterm managements (conventionally-managed and biologicallybased row-crop agricultural systems, along with a primary successional unmanaged system), and they explore the usefulness of grayscale gradients as proxies to determine the microscale spatial distribution of soil organic matter (SOM). Finally, Quigley et al. use the natural difference between carbon isotopes of $\mathrm{C} 3$ and C4 plants to determine how the presence of pores of different sizes affects spatial distribution patterns of newly added carbon immediately after plant termination and then after 1-month incubation. The results indicate that, in the studied soil, pores of $40-90 \mu \mathrm{m}$ size range are associated with the fast influx of new $C$ followed by its quick decomposition, whereas pores $<40 \mu \mathrm{m}$ tend to be associated with $\mathrm{C}$ protection.

The next group of articles deal with microscale aspects of soils related to the presence of plant roots. van Veelen et al. use correlative X-ray CT (resolution $\sim 20 \mu \mathrm{m}$ ) in combination with Magnetic Resonance Imaging (MRI, resolution $\sim 120 \mu \mathrm{m}$ ) to set up groundwork to enable in situ visualization of rootproduced mucilage in soil. Benard et al. also focus their attention on this mucilage. They use a percolation approach to predict the flow behavior in the rhizosphere near the critical mucilage content. At that particular stage, a sufficient fraction of pores is blocked and the rhizosphere turns water repellent. Two other articles deal with the influence that plant roots, by themselves or through chemicals they exude, can have on microorganisms in their vicinity. Rodeghiero et al. combine planar optodes and spatial analysis to assess how tomato roots influence the metabolic activity and growth patterns of the fungus Fusarium oxysporum $f$. sp. lycopersici (Fol), one of the most destructive soil-borne diseases of tomatoes. Using fluorescence microscopy combined with automated image analysis and spatial statistics, Schmidt et al. carry out a gnotobiotic experiment using a potential nitrogen-fixing bacterial strain in combination with roots of wetland rice to explore the distribution of bacterial colonization patterns on rhizoplanes of the rice roots.
Another group of articles in this Research Topic deals with observations of the distribution and dynamics of microorganisms in soils. Chamizo et al. inoculated two cyanobacterial species, Phormidium ambiguum (non N-fixing) and Scytonema javanicum (N-fixing) on different textured soils (from silt loam to sandy), and used scanning electron microscopy to analyze the development of cyanobacteria biocrust and the evolution of selected physicochemical properties of the soils for 3 months under laboratory conditions. Couradeau et al. also worked on biocrusts. They developed methodologies to visualize and quantify the water dynamics within an undisturbed biocrust undergoing desiccation. In particular, using synchrotron-based X-ray microtomography, they were able to resolve the distribution of air, liquid water, mineral particles and cyanobacterial bundles at the microscale. Vermeire et al. assess the reciprocal interactions between soil minerals, SOM, and the broad composition of microbial populations in a 530-year chronosequence of podzolic soils. Choi et al. use a metagenomic sequencing method to assess the distribution of genes encoding for key cellulose-degrading enzymes among aggregate fractions in a fertilized prairie soil. Watteau and Villemin. illustrate with studies involving a variety of soils in different contexts (i.e., five cropped soils, one forest soil, and one Technosol) that Transmission Electron Microscopy (TEM) can be used advantageously to localize microorganisms and deduce their influence within soil structures. In particular, organic matter turnover can be assessed within microhabitats through a combination of TEM, Electron Energy Loss Spectroscopy (EELS) or NanoSIMS. Finally, Juyal et al. address the extent to which it is possible to control the pore geometry at microscopic scales in microcosms made of repacked aggregates, through manipulation of common variables such as density and aggregate size. In addition, they analyze in these microcosms the effect of pore geometry on the growth and spread dynamics of Pseudomonas sp. and Bacillus sp. bacteria following their introduction into soil.

The next group of articles focuses on the use of artificial media to gain a better understanding of the factors that control the distribution and activity of microorganisms in pores. Schlüter et al. introduce an experimental framework relying on simplified porous media (consisting of aggregates of porous, sintered glass beads) that circumvents some of the complexities occurring in natural soils while fully accounting for physical constraints believed to control microbial activity in general, and denitrification in particular. They use this framework to explore the impact of aggregate size and external oxygen concentration on the kinetics of $\mathrm{O}_{2}$ consumption, as well as $\mathrm{CO}_{2}$ and $\mathrm{N}_{2} \mathrm{O}$ production. Guo et al. are interested in how the pore geometry of a soil can affect the extent to which bacteria are able to influence local moisture conditions through the secretion of extracellular polymeric substances (EPS). They systematically measured the rate and extent of water evaporation from pore structures as a function of both EPS concentration and pore size. They used for that purpose three different types of twodimensional chambers: glass capillary tubes with a uniform macropore geometry, emulated soil micromodels representing an aggregated sandy loam pore geometry, and microfluidic capillary arrays to represent a uniform micropore geometry. Using the 
same type of micromodel of a sandy loam soil, Soufan et al. try to ascertain that the fungus Rhizoctonia solani can indeed grow in such an environment, and then to identify and analyze in detail the pattern by which it spreads in the tortuous pores of the micromodel.

Finally, a last group of articles uses theoretical calculations or computer modeling to describe processes that control the interaction of bacteria with pore surfaces, or the activity of bacteria in soils. Bradford et al. present a theoretical method to determine the mean interaction energy between a colloid and a solid-water-interface when both surfaces contain binary nanoscale roughness and chemical heterogeneity, and they illustrate the application of the method to bacterial retention on solid surfaces. Portell et al. explore in silico the hypothesis that the heterogeneous distribution of soil organic matter, in addition to the spatial connectivity of the soil moisture, might account for the observed microbial biodiversity in soils. The analysis rests on a multi-species, individual-based, pore-scale model that is parameterized with data from 3 Arthrobacter sp. strains, known to be, respectively, competitive, versatile, and poorly competitive.

One may wonder to what extent all these 22 manuscripts, published over the last year, have managed to put some color in the schematic diagram of Figure 1, i.e., dissipate a little bit the knowledge gap that existed on many questions at the time the graph was established. We lack the necessary perspective to determine if the articles contained in this Research Topic will contribute to make a serious dent in the gray zones of Figure 1, but it is comforting in this context to see that quite a few articles, either through experiments or modeling, deal head on with the challenges associated with the distribution and activity of microorganisms in soils at the microscale. As mentioned earlier and as illustrated by Baveye et al. in Figure 1, microscale research on the microbial components of soil systems until recently has been seriously lagging behind the work on the physical and (bio)chemical characteristics. It is encouraging to see, among the various articles gathered in this Research Topic, several resolutely engage along this relatively unexplored path.

Arguably as a result of the Research Topic, or at least stimulated by it, the research on the microscale properties of soils is now entering into another phase, where different techniques and disciplinary outlooks will be systematically combined to apprehend more completely the characteristics of microhabitats in terrestrial systems. A number of research groups around the world are now trying to quantify the physical and (bio)chemical features of these microhabitats, as well as to describe as thoroughly as possible the composition and biodiversity of microbial populations they contain. The very recent article by Schlüter et al. (2019) is an excellent example of the type of work that is unfolding in this area. Using a combination of X-ray $\mu \mathrm{CT}$, fluorescence microscopy, scanning electron microscopy and nanoSIMS, these authors are able to study the distribution of bacteria in a soil, and to show that they have a preference toward foraging near macropore surfaces and near fresh particulate organic matter. Juyal et al. (2019) combined X-ray CT with biological thin sections to elucidate the impact of pore architecture on bacterial distribution in soil. They highlighted that when different methods are being integrated, one needs to consider an "appropriate spatial scale" to understand the

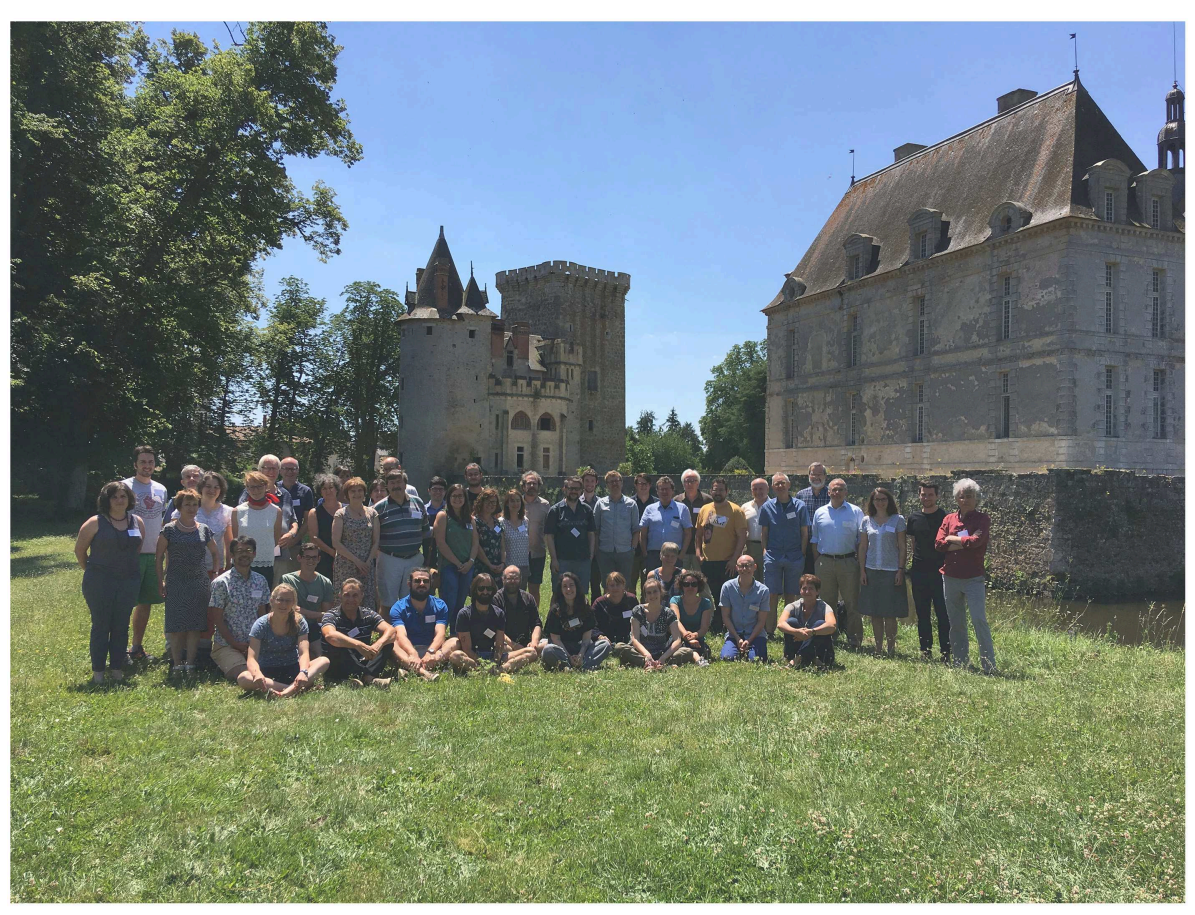

FIGURE 2 | Group picture of the attendees of the Microsoil 2018 workshop, held in the château of Saint Loup Lamairé (Deux Sèvres, France) in June 2018. The group comprised 50 researchers from 7 countries, who for 3 days, debated issues associated with the Research Topic in a very relaxed atmosphere. 
factors that regulate the distribution of microbial communities in soils. It is hoped that these type of interdisciplinary efforts will not only help us understand better what controls the activity of microorganisms in soils, but will also enable us to (finally) make progress on the intimately linked topic of the dynamics of humic substances (e.g., Baveye and Wander, 2019).

We feel confident that within the next few years an increasing focus will be placed on integration of techniques. Progress in this respect will likely be fueled very significantly by the development of an array of new techniques, e.g., single-cell metabolomics or X-rays produced by plasma wave accelerators, which offer great promise for the research on soils and sediments. It may take a significant time, still, to develop the type of macroscopic descriptors of the emergent properties of microbial activity that are all the way in the gray zone in Figure 1, and that we desperately need to predict how soils are likely to react to the changes we impose on them, but at least we now seem to be on track to 1 day get there.

This brief description of the salient aspects of the Research Topic on "Elucidating microbial processes in soils and sediments" would not be complete without mentioning an event that took

\section{REFERENCES}

Alexander, M. (1964). Biochemical ecology of soil microorganisms. Annu. Rev. Microbiol. 18, 217-250. doi: 10.1146/annurev.mi.18.100164.001245

Baveye, P. C. (2015). Grand challenges in the research on soil processes. Front. Environ. Sci. 3:10. doi: 10.3389/fenvs.2015.00010

Baveye, P. C., and Wander, M. (2019). The (bio)chemistry of soil humus and humic substances: why is the "new view" still considered novel after more than 80 years? Front. Environ. Sci. 7:27. doi: 10.3389/fenvs.2019.00027

Eickhorst, T., and Tippkötter, R. (2008). Improved detection of soil microorganisms using fluorescence in situ hybridization (FISH) and catalyzed reporter deposition (CARD-FISH). Soil Biol. Biochem. 40, 1883-1891. doi: $10.1016 /$ j.soilbio.2008.03.024

Foster, R. C. (1988). Microenvironments of soil microorganisms. Biol. Fert. Soils 6, 189-203. doi: 10.1007/BF00260816

Hapca, S., Baveye, P. C., Wilson, C., Lark, R. M., and Otten, W. (2015). Threedimensional mapping of soil chemical characteristics at micrometric scale by combining 2D SEM-EDX Data and 3D X-Ray CT Images. PLoS ONE 10:e0137025. doi: 10.1371/journal.pone.0137205

Hapca, S. M., Houston, A. N., Otten, W., and Baveye, P. C. (2013). New local thresholding method for soil images by minimizing grayscale intra-class variance. Vadose Zone J. 12:vzj2012.0172. doi: 10.2136/vzj2012.0172

Hapca, S. M., Wang, Z. X., Otten, W., Wilson, C., and Baveye, P. C. (2011). Automated statistical method to align 2D chemical maps with $3 \mathrm{D}$ Xray computed micro-tomographic images of soils. Geoderma 164, 146-154. doi: 10.1016/j.geoderma.2011.05.018

Houston, A. N., Otten, W., Baveye, P. C., and Hapca, S. (2013a). Adaptive-window indicator kriging: a thresholding method for computed tomography images of porous media. Comput. Geosci. 54, 239-248. doi: 10.1016/j.cageo.2012.11.016

Houston, A. N., Schmidt, S., Tarquis, A. M., Otten, W., Baveye, P. C., and Hapca, S. M. (2013b). Effect of scanning and image reconstruction settings in X-ray computed microtomography on quality and segmentation of 3D soil images. Geoderma 207, 154-165. doi: 10.1016/j.geoderma.2013. 05.017

Juyal, A., Otten, W., Falconer, R., Hapca, S., Schmidt, H., Baveye, P. C., et al. (2019). Combination of techniques to quantify the distribution of bacteria in their soil microhabitats at different spatial scales. Geoderma 334, 165-174. doi: 10.1016/j.geoderma.2018.07.031

Mueller, C. W., Köbl, A., Hoeschen, C., Hillion, F., Hiester, K., Herrmann, A. M., et al. (2012). Submicron scale imaging of soil organic matter dynamics using place in June 2018 and, although distinct from the Research Topic per se, was nonetheless intimately connected with it. A workshop, entitled MicroSoil 2018, was organized in the château of Saint Loup Lamairé (Deux Sèvres, France) in part to allow a sizeable number of authors of articles published in this Research Topic to get together and interact. A group of 50 researchers from 7 different countries gathered for 3 days (Figure 2), and actively debated about the status of the research, about impediments to its necessarily interdisciplinary character, and about plans for future research activities. A very positive outcome of the workshop is that several researchers from different institutions have decided to collaborate on joint projects (e.g., Vidal et al., 2019). A follow-up MicroSoil Summer school will take place in June 2019, again in Saint Loup Lamairé, and another workshop, MicroSoil 2020, similar to the 2018 one, will be held there in June 2020 .

\section{AUTHOR CONTRIBUTIONS}

All authors listed have made a substantial, direct and intellectual contribution to the work, and approved it for publication.
NanoSIMS - From single particles to intact aggregates. Organ. Geochem. 42, 1476-1488. doi: 10.1016/j.orggeochem.2011.06.003

Mueller, C. W., Remusat, L., and Rumpel, C. (2017). "Characterization of biogeochemical processes at the microscale," in Terrestrial Ecosystem Research Infrastructures, eds A. Chabbi and H. Loescher (Boca Raton, FL: CRC Press), 193-212. doi: 10.1201/9781315368252-9

Nunan, N., Ritz, K., Crabb, D., Harris, K., Wu, K. J., Crawford, J. W., et al. (2001). Quantification of the in situ distribution of soil bacteria by large-scale imaging of thin sections of undisturbed soil. FEMS Microbiol. Ecol. 37, 67-77. doi: 10.1111/j.1574-6941.2001.tb00854.x

Schlüter, S., Eickhort, T., and Mueller, C. W. (2019). Correlative imaging reveals holistic view of soil microenvironments. Environ. Sci. Technol. 53, 829-837. doi: 10.1021/acs.est.8b05245

Schlüter, S., Weller, U., and Vogel, H.-J. (2010). Segmentation of X-ray microtomography images of soil using gradient masks. Comput. Geosci. 36, 1246-1251. doi: 10.1016/..cageo.2010.02.007

Schmidt, H., Eickhorst, T., and Tippkoetter, R. (2012). Evaluation of tyramide solutions for an improved detection and enumeration of single microbial cells in soil by CARD-FISH. J.Microbiol. Methods 91, 399-405. doi: 10.1016/j.mimet.2012.09.021

Solomon, D., Lehmann, J., Kinyangi, J., Liang, B. Q., and Schafer, T. (2005). Carbon K-edge NEXAFS and FTIR-ATR spectroscopic investigation of organic carbon speciation in soils. Soil Sci. Soc. Am. J. 69, 107-119. doi: 10.2136/sssaj2005.0107dup

Vidal, A., Watteau, F., Remusat, L., Mueller, C. W., Nguyen Tu, T.-T., Buegger, F., et al. (2019). Earthworm cast formation and development: a shift from plant litter to mineral associated organic matter Front. Environ. Sci. 7:55. doi: $10.3389 /$ fenvs. 2019.00055

Conflict of Interest Statement: The authors declare that the research was conducted in the absence of any commercial or financial relationships that could be construed as a potential conflict of interest.

Copyright (๑) 2019 Baveye, Otten and Kravchenko. This is an open-access article distributed under the terms of the Creative Commons Attribution License (CC BY). The use, distribution or reproduction in other forums is permitted, provided the original author(s) and the copyright owner(s) are credited and that the original publication in this journal is cited, in accordance with accepted academic practice. No use, distribution or reproduction is permitted which does not comply with these terms. 